\section{穴 Heighten Science \\ P U B L I C I T I O N S Corporation \\ ISSN \\ 2639-6653}

\title{
Nursing Care of ICU Patients Lightly Sedated with Dexmedetomidine
}

\author{
Åsa Engström ${ }^{1 *}$, Maria Johansson ${ }^{2}$, Mia Mattsson ${ }^{3}$ and Ulrica \\ Strömbäck ${ }^{1}$ \\ 'Department of Health Science, Luleå University of Technology, Luleå, Sweden \\ ${ }^{2}$ Intensive Care Unit, Gällivare Hospital, Gällivare, Sweden \\ ${ }^{3}$ Intensive Care Unit 57, Sunderby Hospital, Luleå, Sweden
}

\begin{abstract}
*Address for Correspondence: Dr. Åsa Engström, Department of Health Science, Luleå University of Technology, SE-971 87 Luleå, Sweden, Tel: +46 92049 38 75; Fax: +46 92049 38 50; Email: asa.engstrom@ltu.se
\end{abstract}

Submitted: 18 November 2016

Approved: 20 December 2016

Published: 22 December 2016

Copyright: @2016 Engström et al. This is an open access article distributed under the Creative Commons Attribution License, which permits unrestricted use, distribution, and reproduction in any medium, provided the original work is properly cited.

Keywords: Critical care nurses; Experiences Intensive care; Qualitative content analysis; Sedation

\section{ABSTRACT}

Background: Intensive care patients are often in need of sedation to endure being intubated. Light sedation is increasingly common since it has been proved to offer benefits such as faster recovery to patients.

Aim: The aim of this study was to describe critical care nurses' experiences of nursing patients lightly sedated with dexmedetomidine.

Research Methodology: Qualitative personal interviews were conducted during 2015 with 10 critical care nurses in Sweden. Interview transcripts were analysed using inductive qualitative thematic analysis.

Results: Light sedation of the patient facilitated communication and interaction with him or her, and the relationship between the patient and his or her family members. Dexmedetomidine was described as a fairly new drug, and the critical care nurses stated that they needed more knowledge about it and about sedation scales in order to learn more about the drug's mechanism of action and its potential side effects on patients.

Conclusion: It is important to critical care nurses to learn more about dexmedetomidine and about sedation scales to assess levels of sedation, as light sedation has been shown to benefit the patient as opposed to deep sedation that can increase recovery time.

\section{BACKGROUND}

Critically ill patients in intensive care units (ICUs) often require sedation to endure various medical procedures and treatments [1]. Maintaining adequate levels of sedation is an essential component of critical care nursing, and sedation can be defined as a drug-induced lowering of the level of consciousness [2]. The degree of sedation affects the patient's level of responsiveness and consciousness; it also affects cardiac function and the ability to independently maintain a patent airway with spontaneous breathing [3]. Light sedation may cause greater temporary stress, but it eventually leads to shorter hospital stays, faster recovery, and a lesser degree of perceived stress when the patient has left the hospital [4]. According to [5] keeping patients lightly sedated is an important intervention to limit serious complications like delirium, and she suggests that more research is needed about daily interruption of sedation to better understand what effect it has on critically ill patients. Inadequate sedation can cause unpleasant memories for the patient that are linked to his or her time on the ventilator [6,7]. Deep sedation reduces stress experiences but entails disadvantages such as prolonged ventilator therapy and prevents patient mobilization [8]. More time spent connected to the ventilator often results in the need for a longer weaning time, and a longer ICU stay increases the risk of recurrent nightmares and hallucinations [9].

Intubated and mechanically ventilated patients are unable to express themselves 
verbally [10]. They are dependent on their relatives and on the critical care nurses (CCNs) to interpret their needs and address their symptoms [10]. A CCN is responsible for adjusting sedation and analgesics to an appropriate level [2]. CCNs' understanding of their patients' needs can help provide improved nursing care, for example, by preventing sedating the patient too much or too little $[11,12]$. The Richmond Agitation Sedation Scale (RASS) is a measurement scale used in many ICUs for the graduation of sedation [12,14,7]. According to [13], the RASS and the Sedation-Agitation Scale (SAS) are the most valid and reliable sedation assessment tools for measuring the quality and depth of sedation in adult ICU patients.

There are many sedation drugs available and each has different limitations and side effects [3]. To achieve sedation, drugs such as propofol, midazolam, clonidine, or diazepam have been used [15]. One of the newer sedative drugs is dexmedetomidine, which is said to reduce the need for other drugs such as propofol and opioids [16,17]. Dexmedetomidine (Dexdor ${ }^{\circledR}$ ) is a highly selective $\alpha_{2}$-adrenoceptor agonist with sedative, analgesic and opioid-sparing effects. It is suitable for short- and longer-term sedation for patients in ICUs [18]. Dexmedetomidine can have side effects such as bradycardia, hypertension, and hypotension; it is not a respiratory depressant such as propofol or opioids $[1,16]$.

The indication for the use of dexmedetomidine is that the patient should not require deeper sedation than that which allows the patient to be aroused by verbal stimulus, equivalent to RASS 0 to -3. Cruickshank et al. [19] conclude in their systematic review that dexmedetomidine may be effective in reducing ICU length of stay and time to extubation for critically ill patients in ICUs. Contraindications for its use are hypersensitivity, untreated hypotension, or an acute cerebrovascular condition [16]. After an adjustment, it may take up to an hour before a new stable level of sedation is achieved; the maximum dose should not be exceeded, and another sedating drug should be prepared if agitation occurs with dexmedetomidine, especially during the first hours of treatment [20]. The literature review suggests that ICU patients might benefit from light sedation in a long-term perspective. While physicians prescribe the sedation drugs to be used, it is the CCNs who administer them, and then nurse the patient during the treatment. Therefore, it would be valuable to study CCNs' experiences of nursing patients lightly sedated with dexmedetomidine.

\section{AIM}

The aim of this study was to describe critical care nurses' experiences of nursing patients lightly sedated with dexmedetomidine.

\section{DESIGN}

This study has an inductive descriptive qualitative design [21,22]. The setting is a real-world, naturalistic one, and the data are collected by means of qualitative research interviews, a data collection method that allows the researcher privileged access to people's experiences in order to gain a deeper understanding and a more accurate interpretation of specific phenomena [23,22]. The interviews were analysed with an inductive qualitative thematic analysis as described by [21].

\section{Procedure and participants}

A physician in charge of an ICU in the northern part of Sweden took note of a letter with information about the planned study and then signed a written approval. The nurse manager of the ICU assisted by distributing and informational letter about the study to 12 potential participants. The letters included information about the aim of the study, ethical considerations, and a reply form for indicating informed consent. The inclusion criteria for participation were being a specialist nurse with specialist training in critical care nursing in an ICU with at least two years' experiences of nursing 
ICU patients. The CCNs should also have experience of nursing ICU patients sedated with dexmedetomidine. Twelve (12) of the CCNs who met the criteria were invited to participate in the study. Of the CCNs who were invited to participate, 2 declined and as participation was voluntary, they were not asked why. Their professional experience of intensive care ranged from 3 to 40 years. All were directly involved in patient care and qualified in critical care nursing.

\section{Data collection}

Semi-structured interviews were used as the data collection method $[23,22]$. The authors used an interview guide (Table 1) derived from the literature. According to [23] using an interview guide and semi-structured interviews means having a manuscript covering those questions/topics that the participant will be asked to narrate about to ensure answering the aim of the study. The interviews were conducted in Swedish. The interviews were recorded on digital audio files. Two authors interviewed four participants each, and one author interviewed two participants. Each interview took 30-40 minutes to complete. The interviews took place at an agreed-upon location in consultation with each interviewee. All of the interviewers have experience of critical care nursing. They were all registered nurses with specialist training in intensive care nursing. This means, in the Swedish context, three years university studies to become a registered nurse, and then one year's studies at the university on advanced level to get specialist training in intensive care nursing.

\section{Data analysis with an inductive qualitative thematic analysis}

The entire text was read in order to identify core meanings, i.e., patterns and themes. The first readings of the interviews aimed to develop coding categories. Several readings of the interviews were necessary before the data were coded. The patterns are then descriptive findings, while themes take a categorical form and interpret the meaning of each pattern. The content analysis revealed patterns of CCNs describing their experiences. Those patterns identified seeing benefits for patients, being able to communicate, and experiencing uncertainty about the administration of sedation themes of their experiences [21].

\section{Ethical considerations}

The selection of participants began following approval by the ethics group at the university, according to the Swedish Code of Statutes [24] concerning the ethical review of research involving humans. An oral and written guarantee of confidentiality and informed consent was given to the participants by the authors before the interviews began.

\section{RESULTS}

The analysis resulted in three categories, which are presented in Table 2 and in the text below.

Table 1: Interview guide used in the study.

\section{Please:}

Describe your experiences of nursing sedated patients.

Describe your experience of nursing patients sedated with dexmedetomidine.

Do you experience that patients have any side effects of the sedation? If so, please describe these side effects. Describe your experiences of communication with patients during ventilator treatment.

Describe your experiences of patients' feelings during ventilator treatment and with different kinds of sedation. Describe your experiences of relatives' communications with the patient sedated with dexmedetomidine.

Do you believe that you have enough knowledge about dexmedetomidine? If not, what information do you lack? Follow-up questions: Can you tell me more? How did you feel then? How did that affect you? What did you think then? How did you react? Can you give me an example? Did I understand you correctly ...? 
Table 2: Overview of the results formulated in categories $(n=3)$.

Categories

Seeing benefits for the patients

Being able to communicate

Feeling uncertainty about the administration

\section{Seeing benefits for patients}

Dexmedetomidine was an improvement regarding sedation because the patient could be awake, according to the CCNs. They compared dexmedetomidine to older sedating drugs and noted that dexmedetomidine allowed the patient to be lightly sedated. The patient's heart rate and blood pressure were perceived to be lower during dexmedetomidine treatment. CCNs felt that they were also able to see if patients were uncomfortable. When dexmedetomidine worked, the light sedating effect was obvious.

CCNs described patients sedated with dexmedetomidine as experiencing more normal sleep and feeling more alert in the morning. The CCNs experienced that dexmedetomidine left the patient's body quickly compared to, for example, midazolam, a drug that CCNs experienced could keep the patient asleep for days after the completion of treatment. The CCNs felt that patients accepted the situation better when they were sedated with dexmedetomidine than they did with other sedating drugs. They experienced that the patients were not irritated by the tubes and hoses despite the ventilator.

Dexmedetomidine was administered on intubated and non-intubated patients. A common use was for weaning the patient from the ventilator, and sometimes they used dexmedetomidine as an add-in sedative to reduce the proportion of calories and fat that the patient received in the administration of propofol. The drug was also used for soothing patients to counteract stress and withdrawal, and to enable patients to better tolerate the situation environment. They said that the drug should be prescribed when patients are more awake, which would result in them experiencing a gradual awakening and acceptance of the situation. CCNs described that dexmedetomidine could sometimes be used at nighttime for the patients aiming to become drowsy when it was administered. The degree of sedation was managed by dosage; an increased dose could help patients fall asleep or become more at ease with the situation.

"There's usually much noise and everything here, but you see most often that they come to rest and sleep." (CCN 3)

"They don't wake up suddenly and feel the tube in their throat and panic; instead it becomes a little calmer." (CCN 2)

"It's positive. In fact...you can...adjust and then decide if the patient should sleep from ten at night until six in the morning. A sleeping pill you cannot control [and it] might help [for] a few hours, but dexmedetomidine you can have running continually, and then turn [it] off in the morning until [the patient] wakes up." (CCN 3)

\section{Being able to communicate}

CCNs said that they did not know how much patients sedated with dexmedetomidine remembered from the period of care. CCNs stated that they experienced patients' ability to take in information that was conveyed to them in a better and easier way when sedated with dexmedetomidine. Signals that patients were experiencing wellbeing were conveyed faster when they were lightly sedated with dexmedetomidine. The CCNs said they observed whether a patient was feeling troubled by interpreting the patient's facial expression but exactly how patients experienced the situation was unknown to the CCNs and two of them said it was hard to even interpret their facial expressions. 
CCNs described that intubated, lightly sedated patients could communicate by nodding or by gesturing. Patients received aids such as pain scales or writing boards, which were experienced to simplify communication in most cases. CCNs described that mobilisation became easier when patients had the ability to cooperate. They experienced that patients felt more involved in their own care when there was interaction between the CCN and the patient. CCNs stated that they experienced a new kind of work situation when a patient was lightly sedated, which meant that they had to be present constantly because such patients were not always clear in their minds. The CCNs felt that there was a risk that patients would extubate themselves or remove catheters, such as central venous catheters or nasogastric tubes.

Having a conscious patient was described by CCNs as more demanding because the patient was able to communicate. The workload was experienced as being heavier since it required collaboration with the patient, but this increased workload was experienced as positive because communication between the CCN and the patient was simplified and improved, at the same time as the CCN had to remain close by the patient continually. The responses that patients managed offered answers as to whether CCNs and their nursing care were experienced as positive. The situation could be experienced as time-consuming since CCNs sometimes had to figure out what the patient was trying to convey.

The CCNs described that relatives experienced better contact with the patients when they were lightly sedated. Communication between a patient and his or her relatives could consist of responses like a wink or physical contact. In contrast, the CCNs described that they felt that deeply sedated patients could inhibit relatives' communications with their loved ones. According to the CCNs, lightly sedated patients felt better when they heard their family members' voices because they were able to recognize them.

CCNs felt that it was beneficial for relatives when their loved one was calm; this gave family members a sense of security and peace. If the patient was awake, confused, or worried, relatives could experience discomfort that could lead to them requiring more support. A CCN described that waking up could be experienced as difficult for the patient and family members because the ill patient was not always clear in his or her mind. This situation caused stress and obstacles in communication.

"A deeply sleeping patient's a pretty simple patient to nurse. Now, one should not say 'easy,' as the patient can be really, really sick...but mentally speaking, it's easier when one does not take equal account of what they think and feel, but when one instead starts from oneself." (CCN 2)

"Even though they are a little more awake, it is not always understood what they have. They want to know and it might itch. The nutrition probe goes out more often..." (CCN 10)

"Yes you have got an idea of how they feel. There is always one thing when they are very sick, anesthetized, but you know that is not really until they start to become more awake [that] you know how it really feels when you can communicate with them." (CCN 3)

\section{Feeling uncertainty about the administration}

CCNs stated that each patient's ability to tolerate and accept the environment and the necessary medical treatments was individually determined. The CCNs described that they sometimes felt that it was difficult to determine the correct dosage for the sedative, and their experience was that inadequate sedation could be due to improper dosing. 
CCNs shared experiences of very troubled and agitated patients needing additional sedation with other sedating drugs when dexmedetomidine was perceived as not providing adequate sedation. In cases of insufficient sedation, patients were uncomfortable with the endotracheal tube. The patients then had difficulties synchronising with the ventilator and could also have sleep problems. CCNs described that the addition of sedating drugs such as propofol or Ultiva were used in the form of continuous infusion. They described cases where the patient was critically ill and in need of pain relief and deeper sedation. The addition of other sedating drugs was used in the form of boluses in care or treatment that, depending on the situation, might cause discomfort and pain. CCNs described that not all understood the purpose of the Dexmedetomidine-that the patient would be awake-when the drug was new. Assessment of the level of sedation would be implemented at all shift changes, but all did not use the same scale and some used no scale at all.

"Ifyou manage to get everyone to use the same measurement method, maybe you still get a more uniform assessment." (CCN 1)

"It's a patient in a bed who has a tube in his throat, who sits and writes on a pad, it's really not that way, but that's how it has been marketed. To be able to be awake but still on the ventilator." (CCN 5)

"It's also a guide for others so that they can know how it is to handle, so you can look back on... so it is important to document it as well." (CCN 3)

\section{DISCUSSION}

The results showed that patients were perceived to have a more rapid awakening with Dexmedetomidine treatment in comparison with older sedation methods. Roberts et al. [25] show that continuous sedation over a longer period of time may lead to drug accumulation in the body, it can extend wake time, and also the healthcareassociated infection risk increases. De Jonghe et al. [26] describe the major changes of the muscles of the respiratory tract and throughout the muscular strength of the body after a week of mechanical ventilation, and these consequences are associated with delayed extubation and prolonged mechanical ventilation. Dasta et al. [27] confirm the results by further describing that continuous sedation with Dexmedetomidine results in significantly lower total cost of an ICU compared with infusion of Midazolam that provides deeper sedation than Dexmedetomidine; this is mainly because of the shorter length of stay but also because ventilator associated complications decreases. Shehabi et al. [28] describe that early targeted light sedation should be prescribed at an early stage in the care of the critically ill patient because the patient will not get as big of a loss of muscle strength and mobility, which in turn leads to faster to recovery. Gerlach et al. [16] conclude in their updated review of dexmedetomidine that it is a safe and effective agent for sedation in critically ill patients, but patients with significant cardiac disease may be at risk for severe bradycardia.

The CCNs experienced that light sedation made it possible to communicate readily with patients, who were easily awakened when they were sedated with dexmedetomidine and an interaction took place. This is in line with $[18,8]$ who also show the benefit for patients by having ability to communicate. Karlsson [29] describes that patients may have emotional distress, but when health care workers talk with the patient, camaraderie and interaction occur. According to [30], when the patient is awake, it requires that an interaction take place between the nurse and the patient, which is considered to be beneficial for both CCNs and patients because they can cooperate. This is in line with [31], who describes a caring theory where humans, health, and social services are the main pillars. People's perceptions are subjective and can never be fully understood or interpreted by others. We believe in subjective experiences, in which the patients may be better understood when they are awake. 
Care can then be based on how the patient prefers to be cared for, and person-centered care becomes possible. The National Board of Health (2015) has recommendations for good care and mentions person-centered care, which aims to make health care more personal by understanding the patient's perspective. The person-centered care model is based on information about the patient's values, lifestyle, and personal preferences.

The CCNs felt that patients' relatives experienced a sense of security when the patient was awake. This is confirmed by [32,29], who describe how family members experience a feeling of hope when the patient is awake, as it is difficult to see their ill relative being uncomfortable in the situation. The CCNs described that they had to remain near the patient constantly, for example, due to the risk of extubation, and thus their workload increased. Laerkner et al. [30] describe that it is more demanding to care for an intubated patient who is awake because the situation can be unpredictable. According to [33], obstacles in communication with the patient are experienced as one of the most stressful factors for CCNs, and this can increase the workload. Tanios et al. [34] describe risk factors for unplanned extubation by comparing different sedation strategies and show that most unplanned extubations depend on the patient's own actions. The number of unplanned extubations was lower in patients who had a continuous infusion of sedating drugs. The risk of unplanned extubation increased during intermittent sedation or no sedation.

The CCNs did not have a clear picture of the sedation scale that would be used. Egerod [35] describes flaws in the guidelines of sedation scales. The sedation ratio is sometimes determined by individual experience and local guidelines. In addition, sedation is sometimes used to facilitate CCNs' work situations, despite the knowledge that the patient needs human support rather than sedating drugs [35]. Beck and Johnson [36] argue that the introduction of sedation scales brings experience and resources to the CCN. Such scales also mean a more individual management, based on each different individual patient, about how to handle anxiety, pain, and delirium. Individualized care contributes to patient benefits. According to the Swedish National Board on Health $[37,38]$ care will be based on respect for the equal value of the individual's human dignity, autonomy, and integrity. It also stresses that health care should be carried out and implemented as much as possible in consultation with the patient.

\section{Methodological considerations}

The four authors are registered nurses with specialist training in intensive care and prior understanding of the studied phenomenon. This may affect the findings of the study and considered foreknowledge is necessary to be able focus on the aim of the study, at the same time as it is important to be open-minded and ask follow-up questions about experiences that might seem to be obvious. According to [22], this should be taken into account if the researcher's preconceptions affect the study. The three first authors conducted the interviews individually and used an interview guide to ensure a consistent approach and how the interviews were conducted. They read each other's interviews as soon as they were complete. The interviews and the analysis were conducted in Swedish; the findings were then translated into English. This also might have influenced the findings.

\section{CONCLUSION}

Nursing patients lightly sedated means increased workload for CCNs. However, this increased workload is experienced in a positive manner as they see several advantages for the patient. One is the possibility to communicate; another advantage is that it enhances the possibilities of mobilisation of the patient. Light sedation means that patients are given opportunities for increased participation in their own nursing care. However, the increased workload that results from treatment with light sedation might require that ICUs need increased staff resources to meet patients' needs for effective nursing care. 


\section{REFERENCES}

1. Hoy SM, Keating GM. Dexmedetomidine: A review of its use for sedation in mechanically ventilated patients in an intensive care setting and for procedural sedation. Drugs. 2011; 71: 1481-1501. Ref.: https://goo.gl/9RLMsb

2. Aitken L, Marshall A, Chaboyer W. ACCCN's Critical Care Nursing. Elsevier Health Sciences. 2016. Ref.: https://goo.gl/J4tyT9

3. Fullwood D, Sargent S. An overview of sedation for adult patients in hospital. Nurs Stand. 2010; 24: 48-56. Ref.: https://goo.gl/JK49gC

4. Croxall $\mathrm{C}$, Tyas $\mathrm{M}$, Garside J. Sedation and its psychological effects following intensive care. $\mathrm{Br} \mathrm{J}$ Nurs. 2014; 23: 800-804. Ref.: https://goo.gl/ZibH5p

5. Makic MBF. Daily sedation interruption: current state of the science. Journal of Perianesth Nursing 2014; 29: 501-503. Ref.: https://goo.gl//YUUTo

6. Dotson B. Daily interruption of sedation in patients treated with mechanical ventilation. Am J Health Syst Pharm. 2010; 67: 1002-1006. Ref.: https://goo.gl/vVkgtK

7. Sessler C, Gosnell M, Grap M, Brophy G, O'Neal P, et al. The Richmond Agitation-Sedation Scale: Validity and reliability in adult intensive care unit patients. Am J Respir Crit Care Med. 2002; 166: 1338-1344. Ref.: https://goo.gl/tM0xcm

8. Short J. Use of Dexmedetomine for primary sedation in a general intensive care unit. Crit Care Nurse. 2010; 30: 29-38. Ref.: https://goo.gl/3ck3k3

9. Samuelson K, Lundberg D, Fridlund B. Stressful experiences in relation to depth of sedation in mechanically ventilated patients. Nurs Crit Care. 2007; 12: 93-104. Ref.: https://goo.gl/KMuwz9

10. Engström Å, Nyström N, Sundelin G, Rattray J. People's experiences of being mechanically ventilated in an ICU: A qualitative study. Intensive Crit Care Nurs. 2013; 29: 88-95. Ref.. https://goo.gl/B2xvmM

11. Egerod I, Christensen BV, Johansen L. Nurses' and physicians' sedation practices in Danish ICUs in 2003. A national survey. Intensive Crit Care Nurs. 2006; 22: 22-31. Ref.: https://goo.gl/5k70V7

12. Walker N, Gillen $P$. Investigating nurses' perceptions of their role in managing sedation in intensive care: An exploratory study. Intensive Crit Care Nurs. 2006; 22: 338-345. Ref.: https://goo.gl/hcg30J

13. Barr J, Fraser GL, Puntillo K, Ely EW, Gélinas C, et al. Clinical practice guidelines for the management of pain, agitation, and delirium in adult patients in the intensive care unit. Crit Care Med. 2013; 41 263-306. Ref.: https://goo.gl/70Gp3b

14. Ely E, Truman B, Shintani A, Thomason J, Wheeler A, et al. Caring for the critically ill patient Monitoring sedation status over time in ICU patients: Reliability and validity of the Richmond Agitation-Sedation Scale (RASS). JAMA. 2003; 289: 2983-2991. Ref.: https://goo.gl/Df6e7W

15. Samuelson K. Sedation during mechanical ventilation in intensive care: Sedation practices and patients' memories, stressful experiences and psychological distress. Doctoral diss, Lund University, Sweden. 2006. Ref.: https://goo.gl/WMMCrF

16. Gerlach AT, Murphy CV, Dasta JF. An updated focused review of dexmedetomidine in adults. Ann Pharmacother. 2009; 43: 2064-2074. Ref.: https://goo.gl/hk3w81

17. Szumita PM, Baroletti SA, Anger KE, Wechsler ME. Sedation and analgesia in the intensive care unit: Evaluating the role of dexmedetomidine. Am J Health Syst Pharm. 2007; 64: 37-44. Ref. https://goo.gl/fqwMa3

18. Keating GM. Dexmedetomidine: a review of its use for sedation in the intensive care setting. Drugs 2015; 75: 1119-1130. Ref.: https://goo.gl/zZZAXv

19. Cruickshank M, Henderson L, MacLennan G, Fraser C, Campbell M, et al. Alpha-2 agonists for sedation of mechanically ventilated adults in intensive care units: a systematic review. Health Technol Assess. 2016; 20: 1-117. Ref.: https://goo.gl/PeBWlv

20. FASS (Pharmaceutical Specialities in Sweden). Dexmedetomidine. Ref.: https://goo.gl/MoQqRc

21. Patton MQ. Qualitative research \& evaluation methods ( $4^{\text {th }}$ ed.) London: SAGE. 2015.

22. Polit DF, Beck CT. Nursing research: Generating and assessing evidence for nursing practice. ( $8^{\text {th }}$ ed.) Philadelphia: Lippincott Williams and Wilkins. (2008). Ref.: https://goo.gl/Mh2XBH

23. Kvale S, Brinkmann S. Den kvalitativa forskningsintervjun [The qualitative research interview]. 3th 
ed. Lund: Studentlitteratur. 2014. Ref.: https://goo.gl/CiMVcu

24. SFS 2003:460. Svensk författningssamling [Swedish Code of Statutes]. Ref.: https://goo.gl/8ImX7c

25. Roberts M, Johnson LA, Lalonde TL. Early mobility in the intensive care unit: Standard equipment vs a mobility platform. Am J Crit Care. 2014; 23: 451-457. Ref.: https://goo.gl/IMRNK9

26. De Jonghe B, Bastuji-Garin S, Durand M, Malissin I, Rodrigues $P$, et al. Respiratory weakness is associated with limb weakness and delayed weaning in critical illness. Crit Care Med. 2007; 35: 2007-2015. Ref.: https://goo.gl/SQ7bis

27. Dasta J, Kane-Gill S, Pencina M, Shehabi $Y$, Bokesch $P$, et al. A cost-minimization analysis of dexmedetomidine compared with midazolam for long-term sedation in the intensive care unit. Crit Care Med. 2010; 38: 497-503. Ref.: https://goo.gl/m03KQw

28. Shehabi $Y$, Bellomo R, Reade MC, Bailey M, Bass F, et al. Early goal-directed sedation versus standard sedation in mechanically ventilated critically ill patients: A pilot study. Crit Care Med. 2013; 41: 1983-1991. Ref.: https://goo.gl/eFkwdh

29. Karlsson V. Att vårdas vaken med respirator: Patienters och närståendes upplevelser från en intensivvårdsavdelning [Being nursed awake with respiratory: Patients' and their relatives' experiences from an intensive care unit]. Doctoral thesis, University of Gothenburg, Sweden. 2012. Ref.: https://goo.gl/IW6eUH

30. Laerkner E, Egerod C, Ploug H. Nurses' experiences of caring for critically ill, non-sedated, mechanically ventilated patients in the Intensive Care Unit: A qualitative study. Intensive Crit Care Nurs. 2015; 31: 196-204. Ref.: https://goo.gl/ZxpTcq

31. Eriksson K. Pausen: En beskrivning av vårdvetenskapens kunskapsobjekt [The pause: A description of health science knowledge objects]. Stockholm: Almqvist and Wiksell. 1987.

32. Engström $\AA$, Söderberg S. The experiences of partners of critically ill persons in an intensive care unit. Intensive Crit Care Nurs. 2004; 20: 299-308. Ref.: https://goo.gl/832YGc

33. Pang P, Suen L. Stressors in the ICU: A comparison of patients' and nurses' perceptions. J Clin Nurs. 2008; 17: 2681-2689. Ref.: https://goo.gl/BSj8vE

34. Tanios M, Epstein S, Grzeskowiak M, Nguyen HM, Hyunsoon P, et al. Influence of sedation strategies on unplanned extubation in a mixed intensive care unit. Am J Crit Care. 2014; 23 306-315. Ref.: https://goo.gl/ZGqYTn

35. Egerod I. Uncertain terms of sedation in ICU. How nurses and physicians manage and describe sedation for mechanically ventilated patients. J Clin Nurs. 2002; 11: 831-840. Ref.: https://goo.gl/eBjeaC

36. Beck L, Johnson C. Implementation of a nurse-driven sedation protocol in the ICU. Dynamics. 2008; 19: 25-28. Ref.: https://goo.gl/vRydeu

37. SFS 1982:763. Hälso- och sjukvårdslag [Swedish Health Care Act]. Ref.: https://goo.gl/fZDdG9

38. SFS 2001:453. Hälso- och sjukvårdslag [Swedish Health Care Act]. Ref.: https://goo.gl/VAmtEV 